\title{
Modernidad, Covid-19 y colonialidad en el Perú. Notas introductorias
}

\section{RESUMEN}

La pandemia del coronavirus expresa las tendencias generales del patrón global moderno, cuyas graves amenazas delinean un horizonte gris de colonialidad. El estudio describe algunas ideas centrales en la vida social del Perú, lo importante es resaltar algunos elementos que permiten comprender los momentos actuales. Es interesante destacar para su análisis las transformaciones del patrón global moderno y los posibles impactos que generan en el país.

Palabras clave: Modernidad, colonialidad, vida social y Covid-19.

\section{Modernity, Covid-19 and coloniality in Peru. Introductory notes}

\section{ABSTRACT}

The coronavirus pandemic expresses the general trends of the modern global pattern, whose serious threats outline a gray horizon of coloniality. The study describes some central ideas in the peruvian social life, the important thing is to highlight some elements that allow to understand current moments. It is interesting to distinguish for its analysis the transformations of the modern global pattern and the possible impacts they generate in the country.

KeYwords: Modernity, coloniality, social life and Covid-19. 


\section{Introducción}

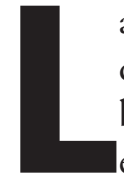

a pandemia del coronavirus expresa las tendencias generales del patrón moderno global y al parecer la crisis abierta exponencia el modelado del curso de la sociedad, cuyas repercusiones continuarán cuando se diluya la enfermedad, marcando su lado más sombrío de la colonialidad. Indudablemente, el mundo proseguirá desplegándose, pero lo hará según el sentido de la historia que interrelaciona modernidad y colonialidad, a no ser que haya un giro profundo en la organización de la existencia social.

En ese sentido, la pandemia es parte del proceso que Aníbal Quijano denomina "crisis raigal de la colonialidad global del poder" (2014, p. 27), después de más de 500 años, desde la conquista de América, probablemente el sistema moderno estaría llegando a sus límites, al acrecentar la destrucción de la naturaleza y agudizar una concentración de la riqueza y desigualdades que amenazan las formas de vida en la Tierra.

La actual crisis de la modernidad global se encuentra teñida, en gran parte, por el malestar que genera el Covid-19, como amenazas severas que trazan un horizonte gris, portador de desconfianza, incertidumbre y miedo de un futuro que puede replicar las fuerzas nebulosas de la colonialidad en todas partes del planeta.

El estudio no espera ser acabado, apenas traza algunas ideas centrales de la vida social, lo importante es destacar algunos elementos cardinales que permitan comprender los tiempos críticos presentes. Interesa rescatar para su análisis las transformaciones del patrón moderno global y los posibles impactos que generan en el Perú.

\section{Covid-19: intensificación de la precarización, pobreza y desigualdad social}

En el mundo la desigualdad social es la principal forma como se extiende la pandemia del Covid-19, los humanos pertenecemos a sociedades inestables que trazan grandes diferencias, que siempre aquejan más a los pobres y dibujan el movimiento y ritmo del desarrollo de la enfermedad.
La particularidad de la crisis del Covid-19 agudiza la precariedad, la pobreza y la desigualdad en las poblaciones de la Tierra. Antes de la pandemia los más ricos existían en un mundo donde la pobreza parecía estar controlada e incluso disminuía, es el caso de Perú, Chile y los propios países desarrollados. En cambio ahora, los grandes ricos se vuelven más y lo hacen en un contexto global donde se incrementa desorbitantemente la pobreza. La desigualdad moderna se desarrolla en forma abierta y cínica.

Una de las consecuencias más importante de la pandemia es que la diferencia entre países desarrollados y los periféricos tiende ha desaparecer en forma definitiva. Aquella divergencia entre las zonas del ser, donde predominaban los derechos y la regulación, y las zonas del no-ser, donde tenían hegemonía la violencia y la dominación (Fanon 2001). El Covid-19 afecta a los países en forma similar, acompañando a la geopolítica mundial, todos incluyen mayorías pobres del sur global y élites del norte global.

Sin embargo, la epidemia sigue las tendencias de la desigualdad global. La vida saludable, las tasas de mortalidad y el acceso a los servicios de salud han sido marcadamente diferentes en períodos anteriores a la pandemia entre las capas medias y las élites con los sectores más pobres, en estos momentos de crisis la vulnerabilidad social se encuentra gravemente afectada por el desarrollo de la enfermedad. En la ciudad de Nueva York la mortalidad de la pandemia afectó más a las poblaciones de hispanas en un 34\% y de negros en un 28\% (La Vanguardia, 2020). En Río de Janeiro la letalidad es 13 veces mayor para las favelas en comparación con los barrios más ricos (Zibechi, 2020). En la ciudad de Barcelona la ocurrencia de la mortalidad es un 26\% menor en los barrios de mayores ingresos que en los barrios con menores rentas (Salas, 2020). En general, las condiciones sociales en la vida de las personas es fundamental, aunque no el único factor, en la expansión del Covid-19.

Ello tiene que ver con el aumento creciente de la riqueza en las élites y la persistente ampliación de la pobreza para las mayorías. En Estados Unidos, en medio de la cuarentena parcial, los más de 600 multimillonarios aumentaron sus fortunas en $434 \mathrm{mil}$ millones de dólares, entre marzo y mayo, mientras que 38.6 millones de personas perdieron sus empleos (Brooks, 2020 ). En ese marco de gran desigualdad, 
el desempleo recorre la paralización de la vida económica, para el mundo se estima la pérdida de 230 millones de empleos a tiempo completo de 40 horas. En los países con mayores ingresos la cifra es de 36 millones, mientras que para los países con menores ingresos se calcula en 14 millones (OIT, 2020a). Los países pobres, aquellos con menores ingresos, tienen las tasas más altas debido al desarrollo de la informalidad, cuyos estimados llegan a 197 millones de personas muy afectados por la reciente pandemia (OIT, 2020b). En ese sentido, la irradiación de la pobreza en el planeta se sitúa entre 40 y 60 millones de personas (Banco Mundial, 2020). Para América Latina la pobreza podría alcanzar los 214.7 millones y la pobreza extrema llegaría a afectar a 83.4 millones de habitantes (CEPAL, 2020). La propagación del Covid-19 en un contexto de modernidad neoliberal expone la brutal concentración de riquezas y la gigantesca desigualdad social.

Se trata de un mundo desbocado, de precariedad, flexibilidad y pobreza para la mayor parte de la población. Destrucción masiva de trabajo, muy difícil de recuperar en el futuro inmediato dadas las condiciones de la revolución tecnológica e inteligencia artificial que redefinen las estructuras productivas. El sistema-moderno no necesita de trabajo asalariado en sus niveles más dinámicos, es probable que se ensanche más el desempleo estructural, el precariado, la informalidad y el trabajo forzado (Standing, 2016).

A la par, se desarrolla una cultura que sustrae el rostro del pobre, para despojarlo de todos los elementos de su identidad, excepto el ser marginados y excluidos, expropiando sus facultades para convertirlos en seres indignos, humillados y privados de sus derechos. Nos enfrentamos a una sociedad que privilegia a las élites clasificándolas como superiores y, de otro lado, clasifica a sectores importantes de la población como seres inferiores y, de esa forma, poder revertir su humanidad (Mejía, 2016).

\section{Destrucción de la naturaleza}

El otro aspecto de la precarización e inferiorización de la población, es la destrucción de la naturaleza por el patrón moderno que puede poner en peligro esta forma de vida existente sobre la Tierra, influyendo de forma determinante en la aparición del Covid-19.
El equilibrio autopoiético del planeta Tierra, formado por la interrelación de lo físico, químico, biológico y lo humano, se ha roto desde hace 500 años por expansión desenfrenada de la modernidad (Lavelock, 2007), afectando la diversidad de la organización de la vida, que tiene en lo humano su dimensión dominante. La destrucción de la naturaleza lleva varios siglos de explotación progresiva, hoy es más grave la supervivencia de las especies, simplemente porque la modernidad global exponenció su mortand; contamos con los medios químicos, herramientas mecánicas, tecnologías sofisticadas e inteligencia artificial para exterminar a los seres vivos, llevando a niveles catastróficos la brecha entre la acumulación ilimitada del capital y los recursos limitados de la naturaleza. Actualmente está en desarrollo la sexta extinción a gran escala de la vida en la Tierra, la tasa de mortandad de seres vivos es 100 veces más alta que la propia tasa natural (Ceballos et al., 2015). De los 8 millones de especies animales y vegetales existentes, 1 de cada 8 están seriamente amenazadas por la modernidad. Se estima que las próximas décadas muchas de las especies puedan desaparecer del mundo (IPBES, 2019). Parece que hemos ingresado irremediablemente a un momento histórico donde la modernidad puede afectar gravemente la propia existencia de la humanidad y toda manifestación de vida en el planeta Tierra.

Antes de la pandemia, en 2019, se desataron gigantescos incendios en la Amazonía sudamericana, generalmente provocados por intereses de ganaderos para erradicar los árboles y las personas. Los incendios más graves se produjeron en Australia, que involucró alrededor de 10 millones de hectáreas, arrasando territorios y biodiversidad, produciendo una hiper criminalidad de mil millones de animales muertos (Elcacho, 2020), cuyas repercusiones recién comienzan a experimentarse para la humanidad.

En ese contexto, la tesis más convincente sobre la origen del Covid-19, de amplio acuerdo entre los investigadores internacionales, es que el virus ha pasado de un animal a otro y de ahí a los humanos. Los animales tienen en sus organismos virus desconocidos, que por su evolución de miles de ańos desarrollaron sus propios anticuerpos, pero por la destrucción de los hábitats naturales llevada por expansión de la modernidad, la destrucción de ecosistemas, del crecimiento constante de las ciudades, la invasión de espacios naturales y el tráfico de animales, con- 
diciones que hacen que las especies se vuelvan muy vulnerables y miles de virus comienzan afectar a los humanos.

Frente a la grave crisis de salud pública directamente vinculada a la pérdida de la biodiversidad del planeta y la destrucción de la naturaleza que empuja a la aparición de enfermedades en el ser humano, los factores son variados, aunque resaltan por su influencia la propagación de los zoonóticos (Suárez et al., 2020, p. 6). Precisamente, la Organización Mundial de la Salud (OMS) estima que el 61\% de los patógenos humanos son zoonóticos y representan el 75\% de todas las enfermedades emergentes durante la última década. Es probable que esta forma de virus del Covid-19 haya surgido al sur de la China y de ahí se expandió por todos los rincones del mundo (Ramonet, 2020).

\section{Patrón moderno digital}

El anuncio de la "era de la información" especificado por su mayor exponente Manuel Castells (1997), producto de los cambios impulsados por la revolución en las tecnologías de la información y la comunicación, apoyados en la asociación de la microelectrónica, las telecomunicaciones y la ingeniería genética, probablemente con la pandemia y sus medidas de encierro de las poblaciones en el mundo hayan acelerado en forma decidida su desarrollo. Acrecentando los procesos de la modernidad en el siglo XXI, que integra en una unidad colonialidad y mundo digital, que transfigura las maneras de vivir y la comunicación entre los seres humanos.

El encierro, la cuarentea y la inmovilidad sujetan a hombres y mujeres en sus hogares, estableciendo que la virtualidad a nivel mundial involucre al conjunto de generaciones de niños, adultos y mayores, y abarque todos los aspectos de la vida social: educación, economía, sociedad, política, cultura, etc., prácticamente el uso de internet se ha duplicado, creciendo en un 80\% (Ramonet, 2020) y se ha convertido en la forma natural de comunicación y socialización entre los humanos.

Todos los sueńos de un mundo plano, de igualdad de redes globales, parece que han terminado abruptamente y más bien hemos ingresado en una sociedad dominada por oligopolios de unas pocas empresas gigantescas de comunicación digital, como Google, Facebook, Twitter, Apple y Amazon, interesadas en convertir todas las actividades de las redes en fuente de datos y en el origen principal del beneficio económico.

Con la pandemia global estamos despuntando un espacio digital que habitar. Sin embargo, la crisis producida por el Covid-19 está trastocando las nuevas tecnologías en herramientas de vigilancia y control individual. Especialmente en los países que rápidamente se han impuesto a la enfermedad como China, Corea del Sur e Israel, donde fueron desarrollados por los servicios de inteligencia, ahora convertidos en mecanismos para monotorizar a las personas, poniendo en cuestión la vida privada y las libertades a cambio de la seguridad. Los teléfonos celulares, los programas informáticos y la inteligencia artificial desarrollaron cámaras de reconocimiento facial, medición de la temperatura, permitiendo obtener miles de datos biométricos que permiten seguir a los individuos minuciosamente (Harari, 2020).

La crisis es un campo político global que posibilita desarrollar en las gentes técnicas verticales de dominio de la vida cotidiana y del control individual. La particularidd del momento actual, que frente al miedo de la pandemia es el propio individuo quien solicita la autosupervición y autocontrol, no es el viejo panóptico que suponía la inspección y seguimiento de manera externa y centralizada por las instituciones del Estado (Bauman, 2007, Cap. I). Podemos estar cursando el camino a formas tecnoautoritarias verticales de dominio de cada persona, no es una casualidad que lo hayan desarrollado con éxito gobiernos no democráticos o impulsados por políticas autoritarias, que cuestionan los derechos y libertades individuales.

Por otro lado, el patrón moderno digital viene alentando principalmente en sus élites ultraconservadoras un proyecto global de "barbarie cultural", que tienen como aspecto central la relegitimación del racismo, especialmente desde la elección del presidente Donald Trump, el 20 de enero de 2017, se vuelve a incorporar en el Estado el discurso racial y la epistemología violenta que ponen en tela de juicio la humanidad de sectores importantes de la población y cuestiona la existencia del cambio climático. Proyecto que hace uso intensivo de medios y redes informáticos 
con el fin de de crear personas poco educadas, mal informadas y enteramente sumisas (Castells, 2019).

La crisis de la pandemia ha potenciado el uso de robots informáticos que ocupan las redes globales, trasmitiendo y modificando los contenidos, se estima entre un millón o dos millones de mensajes antidemocráticos y agresivos (Castells, 2020). En esa situación, es posible que la elección de Trump, Bolsonaro en el Brasil y la salida de Inglaterra de la Unión Europea fueron condicionados por la utilización de los robts informáticos. Nos enfrentamos a la expansión de mensajes ideológicos que se difunden en las redes globales, fundamentalmente generados por fuerzas conservadoras que utilizan la crisis para reavivar los discursos violentos contra sectores de la humanidad y la naturaleza.

En general, la pandemia precipita el desarrollo de una "modernidad sin des/colonialidad" (Quijano, 2014), en otras palabras asistimos a la experiencia de una "modernidad sin modernismo" (Bauman, 213). Se vienen expandiendo activamente la modernidad digital y el crecimiento de sus formas de colonialidad, de la desigualdad social, la destrucción de la naturaleza, los oligopolios, las formas de autocontrol y la imposición de un proyecto de "barbarie cultural". Las promesas originarias de la modernidad de una sociedad justa y de libertad individual se alejan o se buscan anularlas, en un mundo donde tendrían posibilidades de desarrollo lo bárbaro y la realización de las distopías.

\section{Impacto del Covid-19 en el Perú}

Las repercusiones de la crisis de la pandemia en el Perú se analiza en los siguientes puntos esenciales: la situación socioeconómica, el carácter de las políticas públicas y las tendencias generadas en la vida cotidiana de las personas.

\section{Covid-19 y situación socioeconómica}

El Perú transita por un proceso de hondas modificaciones desde las últimas décadas del siglo pasado. Los cambios son producto principalmente de la hegemonía del neoliberalismo. Partimos de la idea que la pandemia en el Perú es muy grave sin llegar a ser los extremos trágicos de EE. UU., Brasil, México, Italia,
Reino Unido (Cuadro 1). Sin embargo, parece que la situación socioeconómica puede llegar a ser más funesta.

Cuadro 1

Contagiados, fallecidos y tasa de letalidad del Covid-19 en algunos países

\begin{tabular}{lrrr}
\hline Países & Contagiados & Fallecidos & Tasa de letalidad \\
\hline Mundo & 7’038,942 & 403,267 & 5.7 \\
EE. UU. & $1 ’ 94,2363$ & 110,514 & 5.6 \\
Italia & 234,998 & 33,899 & 14.4 \\
Reino Unido & 287,621 & 40,625 & 14.1 \\
Brasil & 691,758 & 36,455 & 5.3 \\
México & 117,103 & 13,699 & 11.7 \\
Perú & 196,515 & 5,465 & 2.8 \\
\hline
\end{tabular}

Fuente: Hopkins, J. (2020).

La situación socioeconómica en el Perú es muy adversa por el Covid-19, tendrá un impacto directo sobre el incremento de la precaridad del empleo, la informalidad y el nivel de pobreza. Muchas personas que estaban ingresando y afiazándose en la clase media emergente podrían volver a la condición de pobreza.

La economía peruana en el 2020, por efectos de la paralización provocada por la pandemia del Covid-19, es probable que sufra una contracción cercana del $20 \%$ al 25\%, que incluso llegaría a una reducción del $35 \%$ y $40 \%$ en el PBI, como lo fuera en la Guerra del Pacífico (Seminario, 2020). El modelo de desarrollo actual, que tiene mayor presencia desde la década de los noventa del siglo pasado, es el neoliberalismo, el crecimiento económico lo hace dependiente fundamentalmente del accionar mercado, aunque en los últimos años rearticuló tímidamente la presencia de la actuación estatal en la distribución de recursos para los sectores más vulnerables y en el aumento de las capacidades productivas. Modelo neoliberal vinculado estrechamente a la expansión de la China por medio del "extractivismo informacional" (Calderón y Castells, 2019), debido especialmente a la exportación de productos mineros, que comprenden la destrucción de la territoritorialidad, con la ecológica existente y el aumento de la desigualdad social.

De esa manera, la crisis abierta por la enfermedad amplió crecientemente el desempleo, solo en Lima lo elevó a 1’216,600 entre los meses de febrero y abril 
(INEI, 2020). La pobreza se extiende constantemente, pasaría del $20.2 \%$ estimado para el 2019 al 25\% - 26\% según las informaciones de la CEPAL (2020). La informalidad haría que un $50 \%$ de personas estén en posibilidades de abandonar el encierro en el hogar por la necesidad de buscar algún trabajo (Montoya, 2020). Los sectores poblaciones vulnerables culculadas en $34.2 \%$ para 2018 , alrededor de 10.8 millones de personas, correrían el riesgo de volver a la situación de carencias sociales en el presente, los pobres se calculaban en $29.5 \%$ y podrían llegar a duplicarse en el país por la paralización económica del 2020 (Peñaranda, 2019).

El resultado de las díficiles condiciones sociales en el Perú originan el aumento del desempleo, precariado, informalidad y trabajo forzoso. Riesgo social que puede hacer que el deterioro sea mayor en la salud y en la extensión de la pandemia. La población se desliza a una situación muy crítica, con menos derechos, más dominación y la posibilidad de bordear en el trato deshumanizado.

\section{Las políticas públicas frente al Covid-19}

En el Perú las políticas públicas frente al Covid-19 expresan los agudos resultados de la globalización, en particular en lo referente a la separación entre el poder global y la política local. El poder es más global, sigue la distribución mundial del capital, mientras que a la política local le compete principalmente las actuaciones gubernamentales en relación con las personas. Cuando el Estado busca orientarse a lo global su accionar frente a la población local se torna secundario. La falta de capacidad para controlar los poderes mundiales, se transforma en un principio de incertidumbre y le resta importancia a las instituciones políticas que tienen menos posibilidades de responder a los problemas cotidianos de las gentes (Castells 1997, Cap. 5, Vol. 2). Precisamente, la mayor expresión de las políticas locales en el Perú es el debilitamiento del sistema de salud durante los últimos 40 años, su expresión mayor en el impacto de la pandemia son los 1,061 médicos contagiados y 26 de ellos muertos (EFE, 2020).

En ese cuadro, las políticas públicas frente al Covid-19 se encuentran sometidas a los límites sistémicos globales del poder. Las políticas públicas fundamentalmente se han restringido a las actua- ciones de las transferencias de recursos económicos a los diversos sectores sociales, según el modelo de la mayoría de países como Alemania y Estados Unidos. Por supuesto que las transferencias de recursos evidencian las radicales desiguadades de cada nación, en el Perú se distribuyeron 60 mil millones de soles, en dos paquetes, a los grandes bancos y mayores empresas. A las pequeñas y microempresas les correspondió apenas el 2\%. El bono universal destinado a las personas de escasos ingresos se estima en 5 mil millones de soles. En general, se crea una situación que beneficia 12 veces a favor de los 4 bancos mayores del país (Francke, 2020). El Estado, al querer dirigirse a la globalización del poder, se ve en la necesidad de sacrificar aún más los intereses de la población.

En tiempos de crisis, impulsado por la pandemia, la mayor actuación de la política local del gobierno peruano recae en el mantenimiento del orden. Las otras funciones del Estado se reducen o la comparten con otros poderes. La política local del orden interno frente al Covid-19 se orienta esencialmente a la reclusión de la población en sus hogares. La política local del orden interno intenta combinar el confinamiento espacial de la vivienda con el social de la familia y busca llevar el enclaustramiento obligatorio que impide la salida de sus habitantes.

En esas condiciones, probablemente la política del encierro se encuentra en dificultades serias, no puede impedir que las personas abandonen la inmovilidad, emerge un desborde popular del orden que afecta a sus propios cuidadores; la policía ha sufrido más de 4 mil contagiados y 82 muertos, lo que revela la fragilidad de las intervenciones del confinamiento (Gestión, 2020). Asimismo, la política de inmovilidad expresa delicadas fallas, las disposiciones del 22 de mayo último propiciarían que una tercera parte creciente de la población salga a trabajar, vaya al mercado, al banco, a la peluquería, en otros términos carece de sustento adecuado para poder llegar a ser una cuarentena. La propia ministra de la Producción, declaró que más de seis millones de peruanos con negocio podrán "hacer sus oficios" fuera de los hogares.

La situación del encierro es paralelo y complementario a la pobreza y a sus formas de criminalización (Bauman 2006, p. 117). En particular, la cuarentena tiene serios límites para controlar a los habitantes en el país. En especial, porque se trata de una población caracterizada por la informalidad en 
un $70 \%$, vive al día, sea en pequeños negocios o de actidades callejeras, tiene la urgencia imperiosa de salir fuera de sus viviendas, rompiendo el círculo del confinamiento obligatorio. Además, es importante anotar, la población procedente de la civilización andina, desestima las dávidas o regalos de dinero, posee una alta valoración del trabajo (Adams y Valdivia, 1991).

En situación equivalente, aunque más extrema, se encuentran los 860,000 migrantes venezolanos, que para el 2020, el 93\% se encontraban como informales, con un $83 \%$ sin ingresos por la crisis del Covid-19, sin seguro de salud y en peligro de desalojo de las viviendas en un 52\% (Freier y Brauckmeyer, 2020). Se trata de una población altamente vulnerable que retrata en toda su dimensión el apuro de salir para trabajar. La acción limitada del encierro frente al temor de la pandemia, pone en jaque la propia política local que principalmente gira en torno del orden interno.

De igual forma, se observa en la migración, de regreso al interior del país, la vuelta a las provincias $y$ áreas rurales se ha convertido en un problema serio que afecta la inmovilidad hogareña; se estima en alrededor de 167 mil personas las abandonan Lima por la búsqueda de compañía, solidaridad y alimentos (Zibechi, 2020). La inmigración de regreso resquebraja la política local de confinamiento obligatorio, por la pobreza de sus habitantes, aunque puede llevar a otros encierros en sus lugares de origen y destino.

Por otra parte, la criminalización de la pobreza conlleva la clausura obligatoria extrema. Los últimos años, en el país ha crecido constantemente la población de las cárceles hasta llegar a 97,479, en su mayoría internos que cometieron actos delictivos propio de los pobres, el 73,2\% son delitos asociados contra el patrimonio, contra la libertad sexual y las drogas. La mayoría de cárceles se encuentran en condiciones de grave hacinamiento y peligro de transformarse en espacios infecciosos, convirtiéndolos en instancias de gran vulenerabilidad frente al Covid-19. La respuesta social en las cárceles es la explosión de motines y protestas que directamente cuestionan la autoridad y la política local del encierro en los diversos penales del país: Piura, Chiclayo, Trujillo, Huancayo, Ica, Chiclayo y Lima (Pérez Guadalupe, 2020).
En el Perú el encerramiento muestra la vinculación estrecha entre la pobreza y su criminalización por el intercambio de la población entre ambos ámbitos y, sobre todo, porque expresan las limitaciones del mercado y de las políticas frente al Covid-19, que obligan a sus poblaciones a no resistir el encierro obligatorio. En ese sentido, parece que el miedo no solo tiene que ver con las amenazas de la enfermedad, sino principalmente con la falta de nitidez de las políticas públicas, lo único certero sería la incertidumbre prolongada, esencialmente por el desconocimiento sobre la propia enfermedad y la impotencia para influir en su futuro (Bauman y Dessal, 2014, p. 21).

La política pública del país frente al Covid-19, por un lado, ha seguido la trayectoria de la globalización del capital y, por otra, ha tenido como función central las actuaciones locales de encierro, que han sido desbordadas por la población más pobre, poniendo en crisis las intervenciones del orden interno.

\section{Vida cotidiana en el encierro}

El encierro de estas semanas, debido a la crisis que desató la pandemia, alentó más a la población a situarse frente a la disyuntiva de seguridad versus libertad, que tanto preocupaba a Freud (2013 [1930]). Entre el miedo a la pandemia se ha preferido, en el mundo y el Perú, la seguridad de la inmovilidad en el hogar. La vida cotidiana de las gentes muestra la cesión de una importante parte de la libertad a costa de un aumento en la seguridad del retiro doméstico. Esta libertad mutilada es el sacrificio del proceso de clausura y cuarentena para poder doblegar al Covid-19.

Sin embargo, la información disponible mostró que en marzo el $95 \%$ de la población apoyaba la seguridad del confinamiento, en mayo la aceptación era aprobada por una proporción del 36\% (Ipsos, $2020 \mathrm{a}$ y 2020b), claramente se mostraba una tendencia relativamente decreciente (Pereda, 2020). ¿Qué ocurrió con el proceso de reclusión en el hogar? La explicación hipotética, en parte, tiene que ver con la informalidad de la población; además, por otra parte, se relaciona con el carácter de la vida cotidiana teñida de violencia, generando una crisis en la seguridad del encierro. La pandemia ha desnudado la rudeza de nuestra vida cotidiana.

La mayor parte de las viviendas populares son reducidas, el baño es compartido por todos y carecen 
de los artefactos necesarios para recistir el encierro familiar; la información del 2017 evidencia un tercio de hogares sin refrigerador y el $61,6 \%$ de las casas urbanas tenían entre tres y seis miembros, en muchos casos albergaban a más de un hogar. Asimismo, la vida en las viviendas reproducían momentos transitorios, por lo general para dormir, y luego para proseguir con la jornada de trabajo, ello fue interrumpido bruscamente, ahora con el Covid-19 se trata de reconvertir los espacios definidos de permanencia fija de los habitantes.

Las diferencias entre hombre y mujer muestran que son las mujeres las que llevan la peor parte de la crisis desatada por la enfermedad. La división del trabajo doméstico en la reclusión del hogar, por más colaboración del hombre, las principales tareas recaen en las mujeres. También en épocas del coranovirus el empleo se pierde, los hombres se sienten muy afectados y quizás lleven a desarrollar conductas violentas en el hogar. En efecto, la agresión contra la mujer se incrementa. Entre el 16 de marzo y 19 de abril del período de la pandemia se registraron 3,060 casos de violencia familiar o sexual; 285 personas fueron detenidas por violación sexual y ocurrieron 6 feminicidios, sin tomar en cuenta las 14,000 denuncias recibidas y la situación de las 153 mujeres desaparecidas (Mannarelli et al., 2020). Cuadro social que expresa aún el fundamento institucional de la dominación del patriarcado, carecterizado por facilitar el mayor poder de los varones sobre las mujeres, más allá de los avances de la cultura feminista en el país.

La diversidad de género/sexualidad, en sus grupos más vulnerables, llevó al aumento de la discriminación y agresión, como las mujeres transgénero residentes en el Centro de Lima, en minúsculos cuartos, con un gasto que se hace cada vez más imposible de pagar por la crisis de la pandemia (Lira, 2020). Las situaciones de mayor impacto corresponden a la discriminación pública de mujeres trans en la comisaría de Bellavista y al peligro de hambre de más de 150 mujeres trans del Centro Histórico de la capital (Perú21, 2020). Proceso de discriminación y violencia que, de alguna forma, manifestaría la búsqueda de imponer valores uniformes patriarcales sobre la heterogeneidad de la sexualidad humana.

Los discapacitados, viejos y niños sometidos durante semanas al encierro en el hogar, rayan en una situación cercana al arresto domiciliario, han genera- do graves problemas de salud mental. Las personas se caracterizan porque siempre buscan la compañía directa, el abrazo, la reunión y la cercanía de los otros. No obstante que las relaciones interpersonales se han visto modificadas abruptamente, la prohibición de una socialización presencial es una forma violenta que deshumaniza. La relación entre las personas se han contraído y distanciado, los individuos han tenido que reducirse a la familia durante el encierro, se alejaron de los parientes externos, vecinos, paisanos y amigos. Una larga reclusión que vulnera la condición humana por medio de la coacción física en la vivienda y la pretención de alejarlo de los otros. Esta situación es muy probable que pueda impulsar un serio cuestionamiento a la pretendida seguridad de la población.

El el Perú, la relación entre seguridad y libertad asume características particulares. Dicha relación parece no ceder por la búsqueda de la libertad en las personas, que lo hay, sino que se trastoca por la propia política de encierro en el hogar, por la seguridad, la vida cotidiana de la población lo ha desbordado y roto, transformando la inmovilidad en algo más informal que real.

\section{A manera de conclusión: mercado, Estado y comunidad frente al Covid-19}

En tiempos de crisis, abierto por la pandemia del Covid-19, el patrón moderno digital se expande de modo creciente en el mundo y, a la vez, lo hace su lado oscuro, de la colonialidad, como la desigualdad social, la destrucción de la naturaleza, los oligopolios, las formas de autocontrol y la imposición de un proyecto de "barbarie cultural".

En esas condiciones, cobra especial importancia el mercado, el Estado y la comunidad como las dimensiones reguladoras de la vida social, en épocas de crisis de la actual pandemia estos elementos se tornan centrales en la sociedad. Las políticas públicas, en gran parte, giran privilegiando algunos de estos factores o combinándolos, según la situación de los países.

El orden del mercado ha fracasado en todas sus potencialidades, ha sido la víctima inmediata de la pandemia. Las actuaciones neoliberales vergonzosas de Estados Unidos y Brasil muestran los casos ex- 
tremos en el mundo de la expansión del Covid-19. Estados Unidos, la nación más rica de la Tierra, se muestra incapaz de accionar frente al Covid-19, allí cohabitan la mayor medicina del mundo y una lamentable salud para la población pobre. En Brasil ha primado el dejar hacer y dejar pasar del mercado, con todas las consecuencias graves que han padecido sus habitantes, el presidente Bolsonaro lo llamó "pequeńa gripe" sin importanacia para preocuparse en definr una acción estatal (Paton, 2020).

La actuación del Estado presenta los mayores éxitos en el enfrentamiento de la pandemia, el caso más importante es China por haber detenido los efectos del Covid-19, de alguna forma contando con el apoyo de la población. Sin embargo, China ha recurrido principalmente a formas no democráticas, despóticas del gobierno; las políticas públicas deliberadas han seguido el control y vigilancia tecnológica de las personas por medio de celulares y otros dispositivos informáticos, poniendo en peligro aún más la propia existencia de la libertad personal y la democracia.

La comunidad es la otra dimensión siempre presente, aunque invisibilizada oficialmente y no tomada en cuenta en las políticas públicas. La pandemia del Covid-19, además de la crisis de salud pública global, constituye una crisis comunitaria. Enfrentar la enfermedad demanda mucha solidaridad entre las personas, que únicamente lo pueden ofrecer los niveles institucionales de la comunidad, corresponde a lo que se denomina la sociedad civil. En el Perú las comunidades son las rondas urbanas, rondas campesinas, asociaciones de pobladores y la diversidad organizacional de barrios y pueblos, representan a las agrupaciones "voluntarias" caracterizadas porque los de afuera no pueden entrar fácilmente y los de dentro salir libremente (Bauman, 2006, p. 114). En muchos casos, controlan a la población afectada por la pandemia, sin anular la prerrogativa voluntaria para salir a trabajar $y$, a veces, recurren a la vigilancia de las personas afectadas por el Covid-19. El reto consiste en descubrir formas de colaboración que solo las comunidades lo pueden ofrecer, en momentos de crisis de la pandemia.

Experiencias de la vida social afectada por la pandemia grafican que solo tiene posibilidad el desarrollo de una lógica que vaya más allá del mercado. El miedo a la enfermedad tiene que vencer al individualismo del mercado, hay necesidad de recuperar la energía colectiva que produce el afecto, la confianza de la compañía duradera con los otros y la fortaleza de la comunidad. Punto inicial que posibilite situar en el centro de la sociedad la vida digna de las personas, garantizando que los derechos fundamentales son la condición propia de ser humanos.

Finalmente, es fundamental subrayar que el Perú no ha llegado a situaciones extremas y catastróficas de la pandemia, como Estados Unidos, Italia, Brasil y México, pese a la crisis de la seguridad/encierro de la población. El papel activo e invisibilizado le corresponde fundamentalmente a la comunidad, en la que destaca el factor central de la colaboración y solidaridad entre las personas.

\section{Bibliografía}

Adams, N. y Valdivia, N. (1991). Los otros empresarios. Ética de migrantes y formación de empresas en Lima. IEP: Lima.

Banco Mundial (2020). Pobreza (I). Panorama General, 16 de abril. https://www.bancomundial.org/es/topic/ poverty/overview

BAUMAN, Z. (2013). La cultura en el mundo de la modernidad líquida. México: FCE.

Bauman, Z. (2007). Libertad. Buenos Aires: Losada.

Bauman, Z. (2006). Comunidad. Madrid: Siglo XXI.

Bauman, Z. y Dessal, G. (2014). El retorno del pédulo. Sobre psicoanálisis y el futuro del mundo líquido. Buenos Aires: FCE.

Brooks, D. (2020). "Cuarentena en EU: 600 millonarios más ricos y 38 millones sin empleo". La Jornada, 25 de mayo. México. https://www.jornada.com. $\mathrm{mx} / 2020 / 05 / 25 /$ mundo

Calderón, F. y Castells, M. (2019). La nueva América Latina. México: FCE.

Castells, M. (2020). "Entrevista Wyoming a Manuel Castells. Censurar redes sociales". \#Enelojodelcuervo por Javier, 14 de mayo. https://www.youtube.com/ watch?v=1h1TelRGrP8

Castells, M. (2019). “Seminário Comunicação, Política e Democracia”. FGV, 16 de julio: Río de Janeiro. https:// www.youtube.com/watch?v=I4cizUYfZ18

Castells, M. (1997). La era de la información. Economía, sociedad y cultura. Vol. 2. México: Alianza.

Ceballos, G.; Ehrlich, P.R.; Barnosky, A.; Pringle, R.M. y Palmer, T. M. (2015). "Accelerated modern 
human-induced species losses: Entering the sixth mass extinction". Science Advances, Vol. 1, No 5, http:// advances.sciencemag.org/content/advances/1/5/ e1400253.full.pdf

CEPAL (2020). "El desafío social en tiempos del COVID-19". Informe Especial COVID-19, No 3, mayo. https://repositorio.cepal.org/bitstream/ handle/11362/45527/5/S2000325_es.pdf

Elcacho, J. (2020). “Autralia en llamas. Más de 1.000 millones de animales muertos: escalofriante balance de los incendios". La Vanguardia, 9 de enero. Barcelona. https://www.lavanguardia.com/natural/20200109/472793016199/mas-de-1000-millonesde-animales-muertos-escalofriante-balance-de-los-incendios.html

EFE (2020). "Coronavirus Perú.COVID-19 causa cientos de muertes de médicos, policías y periodistas en Perú". Agencia EFE, 20 mayo. Lima. https://www. efe.com/efe/america/sociedad/covid-19-causa-cientosde-muertes-medicos-policias-y-periodistas-en-pe$\mathrm{ru} / 20000013-4251479$

Fanon, F. (2001). Los condenados de la Tierra. México: FCE.

Francke, P. (2020). "Vigencia dramática: apuntalar la agricultura”. Hildebrant en su trece, No 490, 22 de mayo. Lima.

Freud, S. (2013 [1930]). El malestar en la cultura. Madrid: Alianza.

Freier, L. y Brauckmeyer, G. (2020). "Migrantes venezolanos y covid-19: impacto de la cuarentena y propuestas para la apertura”. Burga, M.; Portocarrero, F. y Panfichi, A. (coordinadores): Por una nueva convivencia. La sociedad peruana en tiempos del COVID-19: escenarios, propuestas de politica y acción pública. Lima: MINSA-PUCP.

Gestión (2020). "Mininter: 82 policías han fallecido y más de 4,000 están contagiados con COVID-19”, 14 de mayo. Lima. https://gestion.pe/peru/coronavirus-peru-ministro-del-interior-informa-que-82-policias-hanmuerto-y-mas-de-4-mil-estan-contagiados-con-covid19-cuarentena-estado-de-emergencia-nndc-noticia/

Harari, Y. (2020). “El mundo después del coronavirus". La Vanguardia, 5 de abril. Barcelona. https://www.lavanguardia.com/internacional/20200405/48285133216/ yuval-harari-mundo-despues-coronavirus.html

Hopkins, J. (2020). "Centro de Recursos: Covid-19: Experiencias e información básica”, 8 de junio.
University \& Medicine. https://coronavirus.jhu.edu/ map.html

INEI (2020). Informe Ténico. Situación del mercado laboral en Lima Metropolitana. Trimestre móvil. 5 de mayo https://www.inei.gob.pe/media/MenuRecursivo/ boletines/05-informe-tecnico-n05_mercado-laboralfeb-mar-abr.2020.pdf

IPBES (2019). Comunicado de prensa: El peligroso declive de la naturaleza «sin precedentes»: Tasas de extinción de especies ‘aceleradas〉. ONU. https://ipbes.net/news/ Media-Release-Global-Assessment

Ipsos (2020a). Informe de Resultados. El COVID-19, marzo. Perú. https://www.ipsos.com/sites/default/files/ ct/news/documents/2020-03/encuesta_de_opinion-_ cuarentena_covid-19.pdf

Ipsos (2020b). Informe de Resultados. El COVID-19, mayo. Perú. https://www.ipsos.com/sites/default/files/ ct/news/documents/2020-05/encuesta_nacional_urbana_mayo_2020_-_el_covid_19_0.pdf

La Vanguardia (2020). "Iglesias de Nueva York harán test de Covid-19 a negros y latinos en los barrios más castigados", 9 de mayo. Barcelona. https://www.lavanguardia.com/internacional/20200509/481049348497/ test-covid-19-iglesias-nueva-york-negros-latinos.html

Lavelock, J. (2007). La venganza de la Tierra. La teoría de la gaia y el futuro de la humanidad. Barcelona: Planeta.

Lira. A. (2020). "La lucha de las mujeres trans en tiempos de pandemia. Para la población estigmatizada, la emergencia nacional ha traído hambre y discriminación". El Comercio, Especiales: Lima. https://especiales.elcomercio.pe/?q=especiales/mujeres-trans-en-tiempos-depandemia-ecpm/index.html

Mannarelli, M.E.; Motta, A.; Yon, C.; L. Figueroa, E. у Sото, K. (2020). “Mujeres, género y pandemia en el perú”. Burga, M.; Portocarrero, F. y Panfichi, A. (coordinadores): Por una nueva convivencia. La sociedad peruana en tiempos del COVID-19: escenarios, propuestas de politica y acción pública. Lima: MINSA-PUCP.

MejíA, J. (2016). "Cultura y dignidad en América Latina. Descolonialidad de la desigualdad social". Investigaciones Sociales, No 37, pp. 315-324. Lima: UNMSM.

Montoya, R. (2020). "'Quédese en casa', mano dura y democracia”. LAMULA.PE, 14 de mayo. Lima. https://rodrigomontoya.lamula.pe/2020/05/14/ quedese-en-casa-mano-dura-y-democracia/ rodrigomontoyar/ 
OIT (2020a). "El COVID-19 y el mundo del trabajo. Estimaciones actualizadas y análisis". Observatorio de la OIT. Segunda edición, 7 de abril de 2020. https:// www.ilo.org/wcmsp5/groups/public/---dgreports/--dcomm/documents/briefingnote/wcms_740981.pdf

OIT (2020b). "El COVID-19 y el mundo del trabajo. Estimaciones actualizadas y análisis". Observatorio de la OIT. Tercera edición, 29 de abril de 2020. https:// www.ilo.org/wcmsp5/groups/public/---dgreports/-dcomm/documents/briefingnote/wcms_743154.pdf

Paton, N.; Shelley, J.; Duwe, E. y Bonnett, W. (2020). "Bolsonaro llama al coronavirus una "pequeña gripe". Dentro de los hospitales de Brasil, los médicos conocen la horrible realidad". CNN, 25 de mayo. https://cnnespanol.cnn.com/2020/05/25/bolsonaro-llama-al-coronavirus-una-pequena-gripe-dentro-de-los-hospitalesde-brasil-los-medicos-conocen-la-horrible-realidad/

Pereda, D. (2020). "Encuesta telefónica del IEP. La frustración crece y pasa la factura a Vizcarra”. La República, 31 de mayo, pp.2-3. Lima.

Peñaranda, C. (2019). "La clase vulnerable alcanza al $34 \%$ de la población peruana”. Informe Económico. Camára de Comerciode Lima - IEDEP. https://www. camaralima.org.pe/repositorioaps/0/0/par/r786_1/iedep_786.pdf

Pérez Guadalupe, J. (2020). "Población penitenciaria: los transgresores”. Manuel Burga, M.; Felipe Portocarrero, F. y Panfichi, A. (coordinadores): Por una nueva convivencia. La sociedad peruana en tiempos del COVID-19: escenarios, propuestas de política y acción pública. Lima: MINSA-PUCP.

Perú21 (2020). "Hambre durante el encierro: el drama de las chicas trans del Centro de Lima”. 11 de abril: Lima. https://peru21.pe/lima/coronavirus-en-peru-hambredurante-el-encierro-el-drama-de-las-chicas-trans-delcentro-de-lima-pandemia-covid-19-lgtbi-noticia/

Quijano, A. (ed.) (2014). Des/colonialidad y bien vivir. Un nuevo debate en América Latina. Lima: URP.

Ramonet, I. (2020). "La pandemia y el sistema-undo". La jornada,25 de abril. México. https://www.jornada. com.mx/ultimas/mundo/2020/04/25/ante-lo-desconocido-la-pandemia-y-el-sistema-mundo-7878.html

SALAS, J. (2020). "La pandemia golpea más a los que menos tienen”. El País, 16 de mayo. Madrid. https://elpais. com/ciencia/2020-05-16/la-pandemia-golpea-a-losque-menos-tienen.html

Seminario, B: (2020). "Si las cosas siguen como están, sino se reactiva, Lima es inviable”. Gestión, 12 de mayo. Lima. https://gestion.pe/economia/bruno-seminariosi-las-cosas-siguen-como-estan-si-no-se-reactiva-limaes-inviable-noticia/

Standing (2016). El precariado una nueva clase social. Barcelona: Pasado y Presente.

Suárez, L.; Asunción, M.; Rivera, L. y otros (2020). Pérdida de naturaleza y pandemias. Un planeta sano por la salud de la humanidad. Madrid: WWF España.

Zibechi, R. (2020). "La idiotez de la vida urbana". La Jornada, 8 de mayo. México. 